\title{
HISTÓRIA, LEGISLAÇÃO E ATO INFRACIONAL: privação de liberdade e medidas socioeducativas voltadas aos infantojuvenis no século XX
}

\author{
Camila Serafim Daminelli*
}

\begin{abstract}
RESUMO: Durante o século XX o Estado brasileiro buscou reeducar a população infantojuvenil infratora através de sua inserção em centros erguidos para esse fim. Primeiramente pautando-se pelo Direito do Menor (1927), em seguida, através da Doutrina da Situação Irregular (1979), os infratores foram sujeitos prioritários para internação, dado o potencial que neles se via para desordem pública e como demanda da criminalidade adulta. A partir da promulgação do Estatuto da Criança e do Adolescente (1990), medidas socioeducativas em regime aberto foram instituídas e valorizadas, apresentando-se o abrigamento como último recurso. Propõe-se uma análise das medidas previstas em lei para a responsabilização dos infantojuvenis ao longo do século XX, no Brasil e, à luz do tempo presente, fazer algumas considerações sobre as medidas socioeducativas prescritas pela legislação em voga.
\end{abstract}

PALAVRAS-CHAVE: Ato infracional; Legislação infantojuvenil do século XX; Medidas socioeducativas; História do Tempo Presente.

\section{History, legislation and offense: deprivation of liberty and socio-educational measures aimed at children and adolescents in the 20th century}

\begin{abstract}
During the twentieth century the Brazilian State sought to reeducate the minors offenders by their insertion in centers built for this purpose. First based on Minor's Rights [Direito do Menor] (1927), then through the Doctrine of the Irregular Situation [Doutrina da Situação Irregular] (1979), the offenders were priority subject for internment, because of their noticeable public disorder potential and as adult crime demand. Since the enactment of the Child and Teenager Statute [Estatuto da Criança e do Adolescente] (1990), educational measures in open regime was established aiming the reintegration of the offender to social life, presenting the shelter as a last option to be used. It is proposed to analyze the measures provided by law for accountability of child and youth people throughout the twentieth century, in Brazil and make some considerations about educational measures prescribed by actual law.

KEYWORDS: Offense; Child and youth legislation of the twentieth century; Social-educational measures; History of Present Time.
\end{abstract}

\section{Historia, legislación y delito: privación de libertad y medidas socio-educativas para niños y adolescentes en el siglo $\mathrm{XX}$}

RESUMEN: En el siglo XX el Estado brasileño ha buscado reeducar los considerados menores desde su inserción en refugios construidos con esa finalidad. Primeramente basado en el Derecho del Menor [Direito do Menor] (1927), después por la Doctrina de la Situación Irregular [Doutrina da Situação Irregular] (1979), los autores de delito han tenido prioridad en la internación, dado su potencial para el desorden público y como demanda de la criminalidad adulta. Desde la implantación del Estatuto del Niño y Adolescente [Estatuto da Criança e do Adolescente] (1990), medidas socio-educativas en régimen abierto han sido valoradas, presentándose el refugio como recurso final. Se propone un análisis de las medidas socio-educativas previstas en la ley para la responsabilidad del niño y adolescente autor de delito a lo largo del siglo XX, en Brasil y, a la luz del tiempo presente, hacer consideraciones acerca de las medidas prescritas en la legislación actual.

PALABRAS-CLAVE: Delito; Legislación infanto-juvenil en el siglo XX; Medidas socio-educativas; Historia del Tiempo Presente.

\footnotetext{
*Doutoranda em História pela Universidade do Estado de Santa Catarina. Membro da REHIAL - Red de Estudios de Historia de las Infancias en América Latina. Contato: Universidade do Estado de Santa Catarina, Laboratório de Relações de Gênero e Família, Av. Me. Benvenuta, 2007, Itacorubi, 88036-500, Florianópolis-SC, Brasil. camis.hst@gmail.com
} 


\section{Considerações iniciais}

A população infantojuvenil brasileira fora tutelada por três legislações, ao longo do século XX. Cada uma delas foi gestada sob a perspectiva de doutrinas jurídicas que se apresentavam aos olhos dos governantes do país como as mais acertadas para lidar com os problemas das crianças e dos adolescentes de seus respectivos momentos históricos. $\mathrm{Na}$ década de 1920, quando o Estado brasileiro construira o primeiro corpo de leis da América Latina voltado especificamente à população infantojuvenil - o Código de Menores de 1927 - a criminalidade e o abandono dos assim chamados menores ${ }^{1}$ eram problemas sociais latentes das grandes cidades. O ideário republicano galgava a infância como o lugar do futuro, fosse na condição de cidadão ou de trabalhador: a Doutrina do Direito do Menor, ou salvacionista, como ficou conhecida, tinha como meta salvar as crianças brasileiras da pobreza e da marginalização.

Quando da promulgação do Novo Código de Menores, em 1979, não apenas os termos do debate haviam sido alterados, mas também o cenário político do país passara por mudanças significativas. Não se tratava mais de combater a criminalidade infantojuvenil, mas prevenir os atos infracionais, entendidos a partir das lentes da Doutrina da Situação Irregular: crianças e jovens pobres eram infratores ou infratores em potencial, o que justificava a intervenção do Estado. Essa doutrina fora gestada no Brasil no contexto da Doutrina de Segurança Nacional, levada a cabo pelo regime militar que tomou o governo do país em 1964 e tinha como palavra de ordem a noção de prevenção. No vocabulário da Fundação Nacional do Bem Estar do Menor - FUNABEM, por prevenção deveriam entender-se "medidas adotadas para evitar a manifestação de fenômenos prejudiciais à ordem individual ou social"2.

No entardecer do século XX, em 1990, os debates internacionais acerca dos direitos das crianças e dos adolescentes, somados aos movimentos sociais civis do período de reabertura política proporcionaram a formulação de um novo corpo doutrinário e jurídico, o Estatuto da Criança e do Adolescente - ECA. Este estatuto, pautado pela Doutrina da Proteção Integral, se baseia na noção de que as crianças e os adolescentes são sujeitos de direito prioritários e está em voga no país há mais de vinte e cinco anos. Diferente das legislações infantojuvenis que o precederam, o ECA não aborda com centralidade uma ou outra situação envolvendo a população da qual se ocupa, tratando de abarcar com detalhamento todas as faces da promoção de direitos envolvendo as crianças e os adolescentes. 
As três legislações citadas - o Código de Menores (1927), o Novo Código de Menores (1979) e o Estatuto da Criança e do Adolescente (1990) - formam o corpus documental a ser analisado neste estudo. ${ }^{3}$ Através da legislação investigamos quais mecanismos foram propostos pelo Estado brasileiro para a responsabilização de crianças e adolescentes em situação de conflito com a lei, ao longo do século XX. A abordagem cronológica, a nortear estas linhas, não deve ser entendida como encaminhamento positivado ou progressista no que diz respeito à penalização infantojuvenil. Como produto do social, a lei se constitui de permanências, tentativas e retrocessos, não sendo um dado universal que avança naturalmente com o passar do tempo.

Análises do campo do Direito - como a que se busca construir - levam em consideração a formação e o funcionamento do meio judicial, bem como as diferenças conceituais fundamentais entre Direito, Lei e Justiça, para a compreensão do chamado Jogo da lei. De acordo com a historiadora e jurista Jeanne Silva, tal jogo é o meio pelo qual diversos agentes articulam seus atos de forma política e deliberadamente intencional, dentro e fora da letra da lei. Diante do estabelecimento do campo, dos agentes, dos discursos, das regras e procedimentos, o jogo passa a ter um desenrolar incerto, que ultrapassa a descrição do aparato legislativo ${ }^{4}$. Uma vez compreendido que a ação judicial vai além do legalismo, o entendimento de jurídico mobilizado por esse estudo requer também que se evidencie a dimensão do político, "sendo essa máxima fundamental nas explicações ou nos julgamentos sobre a presença ou ausência de práticas democráticas ou de justiça social alcançados no funcionamento judicial" ${ }^{, 5}$.

O sociólogo Pierre Bourdieu, ao pontuar que a lei na sociedade ocidental, desde a emergência do Estado moderno, deve ser entendida como campo de lutas, produto de embates entre diferentes grupos sociais, sustenta que o Direito não pode ser entendido como manifestação da vontade de um determinado sujeito histórico, seja ele coletivo ou individual. Em concordância com este autor, entende-se que a análise do campo jurídicopolítico implica no reconhecimento de esferas distintas e complementares: a produção da lei e a sua posterior aplicação ${ }^{6}$. Para fins desta análise, pontua-se que a legislação permite muito pouco o estudo da aplicabilidade de uma doutrina, pois esta lhe é posterior; daí a opção pelo estudo da lei a partir de seu conteúdo e do contexto de sua produção. A legislação será lida iluminando-se, portanto, o contexto histórico no qual emerge, bem como as possibilidades colocadas pela letra da $\operatorname{lei}^{7}$. 


\section{Medidas aplicáveis aos delinquentes no Código de Menores de 1927}

As primeiras décadas do Brasil republicano foram marcadas por preocupação crescente com duas faces da infância e da adolescência: as crianças abandonadas e os menores criminosos. A diferenciação em termos conceituais sinaliza uma compreensão, que se consolidaria após a promulgação do Código de Menores: para as crianças abandonadas, prevaleceram os esforços assistenciais oriundos da iniciativa religiosa, enquanto os assim chamados delinquentes se tornaram menores, filhos do Estado, para os quais se concentraram as ações dos poderes públicos ${ }^{8}$. Segundo a historiadora Silvia Arend, os discursos formulados pelas elites brasileiras nos anos 1920 propalavam a necessidade de salvar as crianças brasileiras do ócio e do vício. Desse espírito da época resulta o nome da doutrina que embasa o Código de Menores de 1927: salvacionista 9 . Já em sua faceta judiciosa, esse corpo de leis instaurou um Direito Penal do Menor ao prescrever a imputação de uma pena ao infantojuvenil acusado de crime ou contravenção, ainda que considerasse as especificidades da população a qual se dirigia.

Voltado particularmente à prole das famílias pobres, operando na lógica dos abandonados versus delinquentes, o Código de Menores de 1927 parece ter enveredado por uma área social que ultrapassava em muito as fronteiras do jurídico, ao propor medidas protetivas e também assistenciais para a os infantojuvenis. Sua promulgação fora considerada um logro dos esforços de quase vinte anos de debates sobre os problemas da infância e da adolescência. Segundo a socióloga Irene Rizzini,

\footnotetext{
O que impulsionava era "resolver" o problema dos menores, prevendo todos os possíveis detalhes e exercendo firme controle sobre os menores, através de mecanismos de "tutela", "guarda", "vigilância", "educação", "preservação" e "reforma". (...) A legislação reflete um protecionismo, que bem poderia significar um cuidado extremo no sentido de garantir que a meta de resolver o problema do menor efetivamente seria bem resolvida ${ }^{10}$
}

Naquele momento histórico, de acordo com o historiador Marco Antônio Cabral dos Santos, os centros urbanos do país viviam processos ímpares. O solapamento do sistema escravista e a entrada maciça de mão de obra imigrante resultaram numa profunda transformação do quadro social do mundo urbano. $\mathrm{O}$ crescimento populacional fora vertiginoso, a industrialização se desenvolvia a passos largos, o pequeno comércio e a emergência de uma classe média burocrática e profissional consolidavam o modelo de produção capitalista sem, contudo, ser acompanhada pelo progresso nas condições sociais e habitacionais da cidade. A ampliação do mundo urbano e o aperfeiçoamento dos aparelhos policiais indicavam o aumento da criminalidade e da gatunagem, esta entendida como um 
conjunto de delitos de menor relevância, sendo os menores os mais reincidentes autores. Com relação à cidade de São Paulo, entre os anos 1900 e 1916, o autor afirma o seguinte:

As estatísticas mostram que os menores eram responsáveis neste período por $22 \%$ das desordens, $22 \%$ das vadiagens, $26 \%$ da "gatunagem", $27 \%$ dos frutos e roubos, $20 \%$ dos defloramentos e $15 \%$ dos ferimentos. Estes dados indicam a menor agressividade nos delitos envolvendo menores, que tinham na malícia e na esperteza suas principais ferramentas de ação; e nas ruas da cidade, o local perfeito para pôr em prática as artimanhas que garantiriam sua sobrevivência ${ }^{11}$.

Neste contexto, o primeiro Código Penal da República, de 1890, autoriza a fundação de uma Colônia Correcional para o enclausuramento e correção pelo trabalho dos menores considerados vadios e vagabundos, a permanecerem até os $18 \operatorname{anos}^{12}$. Para os pequenos mendigos, viciosos, abandonados e criminosos maiores de 09 e menores de quatorze anos, seria criado um Instituto Disciplinar destinado a abrigá-los até os 21 anos ${ }^{13}$. Portanto, quando da promulgação do Código de Menores de 1927, pelo menos na Capital Federal e na emergente cidade industrial que se tornava São Paulo, o modelo de internação de menores já estava disponível para servir ao aparato jurídico vindouro. O internamento em institutos disciplinares e correcionais, nas primeiras décadas da República, se pautava no ideário da correção via disciplina do trabalho, considerado o principal recurso para a regeneração daqueles que não se enquadravam no regime produtivo vigente ${ }^{14}$.

De acordo com o Capítulo VII do Código de Menores de 1927, referente aos menores delinquentes, adolescentes menores de 14 anos que praticassem atos tipificados como crime ou contravenção não sofreriam ação judicial de espécie alguma, sendo medidas cabíveis apenas a averiguação e o armazenamento das informações relevantes, bem como o estudo da situação social, moral e econômica dos pais ou de pessoa com quem coabitassem. A partir deste estudo de caso, o menor poderia ser enviado a um "asylo casa de educação, escola de preservação ou [se] confiará a pessoa idonea por todo o tempo necessario á sua educação", caso fosse considerado abandonado, pervertido ou em vias de o $\operatorname{ser}^{15}$. Nessas situações, entende-se que as Colônias Correcionais fossem as instituições mais adequadas para o encaminhamento do menor, de acordo às características das mesmas. Caso não fosse considerado pervertido ou abandonado, caberiam advertências do Juiz de Menores aos pais ou a quem tivesse sua guarda. Cabe lembrar que, até a promulgação deste Código, a idade mínima para que se instaurasse um processo penal não era 14 anos, mas os nove anos completos.

Para a faixa etária compreendida entre 14 anos completos e 18 anos incompletos, a lei sugeria que se instaurasse processo [penal] especial. Este consistia na apuração do 
delito, na situação social, moral e econômica dos pais ou pessoa que tivesse sua guarda e na perversão do mesmo. Sendo o menor abandonado, pervertido ou em vias de o ser, seu encaminhamento seria a uma Escola de Reforma ou Instituto Disciplinar, instituição distinta daquela voltada aos menores de 14 anos, ou que funcionasse em regime separado. O tempo mínimo de permanência do adolescente em instituições de reforma era de três anos e o período máximo, de sete anos.

No caso de crime ou contravenção considerada grave, poder-se-ia imputar pena a maiores de 16 e menores de 18 anos segundo tipificação prevista no Código Penal de 1890. A diferença, nestes casos, com relação ao público adulto, seria o cumprimento da pena em ambiente apartado dos maiores de 18 anos. A duração da pena era a mesma sugerida para a população adulta. No entanto, de acordo com o Art. 86, em hipótese alguma um menor de 18 anos poderia permanecer recolhido à prisão comum, quer dizer, junto a sentenciados comuns, independente do motivo pelo qual tivesse sido apreendido ${ }^{16}$. Na falta de estabelecimentos apropriados, o sistema carcerário poderia ser local de cumprimento da sentença, ainda que o caráter da mesma fosse educativo ou disciplinar, ao invés de penitenciário.

O corte etário dos 18 anos completos não se configurava um dado cabal para a instauração de penalidades segundo o universo adulto. Para os indivíduos compreendidos na faixa etária dos 18 aos 21 anos completos havia penas leves, no caso de contravenções de baixa periculosidade: vadios, mendigos e capoeiras menores de 21 anos poderiam ser enviados às Colônias Correcionais pelo período de um a cinco anos visando a sua reeducação em termos de disciplina pelo trabalho. De maneira similar, o indivíduo menor de 18 anos que houvesse cometido crime ou contravenção leve, fosse comprovada sua boa índole ou apresentasse comportamento exemplar em instituição correcional, poderia ter, por parte do Juiz de Menores, extinta sua penalidade ou ser colocado em medida de liberdade vigiada a qualquer momento do processo ou da averiguação do sinistro ocorrido.

A leitura do conjunto de artigos que compõem o Código de Menores de 1927 sugere que havia um tema de central importância para os legisladores da época: a regulamentação do trabalho dos menores. O Capítulo IX, que trata deste tema, juntamente com o que aborda as atribuições das autoridades competentes, é o mais detalhadamente desenvolvido nesta legislação. Esta parecera legitimar o objetivo de manter a ordem almejada à medida que prometia extirpar os males do abandono e da delinquência pela raíz: fosse consolidando as 
relações laborais das crianças e dos adolescentes ou tentando inculcar nos menores a disciplina e o valor pelo trabalho, nos institutos erguidos para esta finalidade.

No que se refere à análise dos Capítulos VII e VIII do referido Código - Dos menores delinquentes e Da liberdade vigiada - entende-se que para os menores considerados delinquentes, criminosos, ou em vias de o ser o internamento era praticamente a única medida aplicável: independente da necessidade ou não de processo especial e da atribuição de uma pena, quaisquer crianças e adolescentes autores de crime ou contravenção passariam uns poucos meses, no mínimo, em regime fechado de internação para reeducação, correção ou disciplinamento. Este padrão é sugerido pela legislação, ainda que pudesse vir a ser acompanhado pela obrigação de reparar o dano causado e pela possibilidade de ter a sentença de liberdade vigiada, em algum momento, proferida pelo Juiz de Menores.

\section{Doutrina da Situação Irregular: a FUNABEM e o Novo Código de Menores}

Em se tratando da legislação infantojuvenil brasileira, Rinaldo Segundo situa a Doutrina da Situação Irregular como intermediária entre as doutrinas da Proteção Integral, pela qual se pauta o ECA e a do Direito Penal do Menor, escopo do Código de Menores de 1927. Por um lado, não garante direitos universais ao infantojuvenil enquanto sujeito de direitos, mas, por outro,

se diferencia da doutrina do direito do menor porque não se "preocupa" com o menor apenas quando esse é delinquente, isto é, quando comete um ato tipificado como crime. Daí viria o caráter intermediário da doutrina da situação irregular. Segundo os seus defensores, não apenas em casos de delinquência, mas também, em casos que poderiam levar a delinquência, tal como, a carência financeira, moral e jurídica do menor encontrariam amparo na ordem jurídica ${ }^{17}$.

No entanto, considera-se importante levar em conta, para além do ideário jurídico, o contexto de implementação das leis para mensurar as positividades, as rupturas ou permanências apresentadas pelo seu conteúdo, pois elas foram gestadas, ao fim e ao cabo, para ser colocadas em exercício e servir a determinados usos.

No interím dos dois Códigos de Menores, o Brasil se transformara. Passara dos governos populares e trabalhistas de Getúlio Vargas para os da tecnocracia dos generaispresidentes. Pelo menos desde meados da década de 1950, quando o Serviço de Assistência ao Menor - SAM entrara em colapso, os legisladores brasileiros desejavam a atualização do Código de Menores, o que fora ocorrer apenas em 1979. O Novo Código de Menores, como 
ficara conhecido esse corpo de leis, fora redigido pela Associação Brasileira de Juízes de Menores, sendo a tão propalada renovação mera formalização da doutrina jurídica da Situação Irregular, já em voga no país desde a criação da Fundação Nacional do Bem Estar do Menor ${ }^{18}$.

Cabem algumas considerações sobre estes dois órgãos que centralizaram as ações voltadas aos infantojuvenis no Brasil, durante grande parte do século XX: o SAM e a FUNABEM. De acordo com Irma Rizzini ${ }^{19}$, os debates acerca da criação de um órgão que centralizasse as ações públicas e privadas voltadas aos infantojuvenis, no país, datam da primeira década do século XX. O SAM tornou-se uma realidade na década de 1940, adquirindo âmbito nacional em 1944. Eram funções deste órgão a sistematização e orientação dos serviços de assistência aos menores desvalidos e delinquentes, bem como proceder à investigação social e ao exame médico-psico-pedagógico dos menores.

Tendo construído para si uma derradeira imagem negativa - apelidado de Escola do Crime e Sem Amor ao Menor - não restava alternativa ao regime militar instaurado em 1964 que a substituição do SAM. Para além da má fama, ainda segundo Rizzini, havia outras razões para que fosse extinto: sua atuação era restrita, basicamente, ao Distrito Federal, e - o que era considerado pior - a internação de menores encaminhados pelo Juizado de Menores era o modelo básico de atuação deste órgão de assistência. Como demonstrado anteriormente, a legislação menorista de 1927 dava subsídios para esta prática.

Ao finado órgão veio substitui-lo a FUNABEM, "fruto da impiedosa crítica aos métodos e resultados do SAM, bem como da concretização e consolidação das propostas formuladas desde o momento em que se pensou, pela primeira vez, na radical transformação de suas estruturas e práticas"20. Descriminando-se suas competências, evidenciava-se a amplitude da esfera de atuação e a predominância do conceito de prevenção frente à política de internação. Isto porque a internação ia de encontro ao ideário da família, por retirar a prole do convívio familiar, bem como se apresentava como uma prática inadequada, porque onerosa em demasia para uma política de massa. Já por prevenção entendia-se ações voltadas a combater o abandono, o perigo moral e a inadaptação do menor, para transformá-lo em cidadão útil à sociedade.

Desde fins dos anos 1950, as mudanças sociais aceleradas impulsionavam um avassalador processo de urbanização. De acordo com o cientista político Arno $\operatorname{Vogel}^{21}$, o êxodo rural, responsável por uma urbanização prematura, estimulava um fluxo constante 
de pessoas que deixavam seus locais de origem para povoar as periferias das cidades em busca dos padrões de vida enaltecidos pelo desenvolvimento com segurança nacional. O surgimento das regiões metropolitanas corria em paralelo com a expansão da pobreza, pois o mercado de trabalho era incapaz de absorver todo esse contingente, excessivo quanto ao número e limitado enquanto mão de obra qualificada. No âmbito desta questão social figurava, a olhos nus, uma questão do menor, já desgovernada em fins da década de 1970.

Quando da promulgação do Novo Código de Menores, a FUNABEM já havia incorporado à outrora imagem negativa do SAM - da qual era a herdeira inevitável - uma série de outras, advindas do fosso entre o discurso propalado e a operacionalização de sua política. Talvez a renovação no campo jurídico buscasse dar fôlego ao decadente regime militar, que não conseguira promover a adequação da Doutrina de Segurança Nacional aos preceitos preventivos da FUNABEM, gerando um contingente de mais de $50 \%$ da população brasileira - ou $1 / 3$ dos infantojuvenis - a considerar-se em estado de marginalização ${ }^{22}$.

De acordo ao Art. $1^{\circ}$ do Código de Menores de 1979, esta legislação dispunha sobre assistência, proteção e vigilância a menores até 18 anos, que se encontrassem em situação irregular e em casos expressos, a menores entre 18 e 21 anos. As medidas de caráter preventivo, no entanto, poder-se-iam aplicar a quaisquer menores de 18 anos de idade, independente da sua situação. A lei definia em situação irregular o menor:

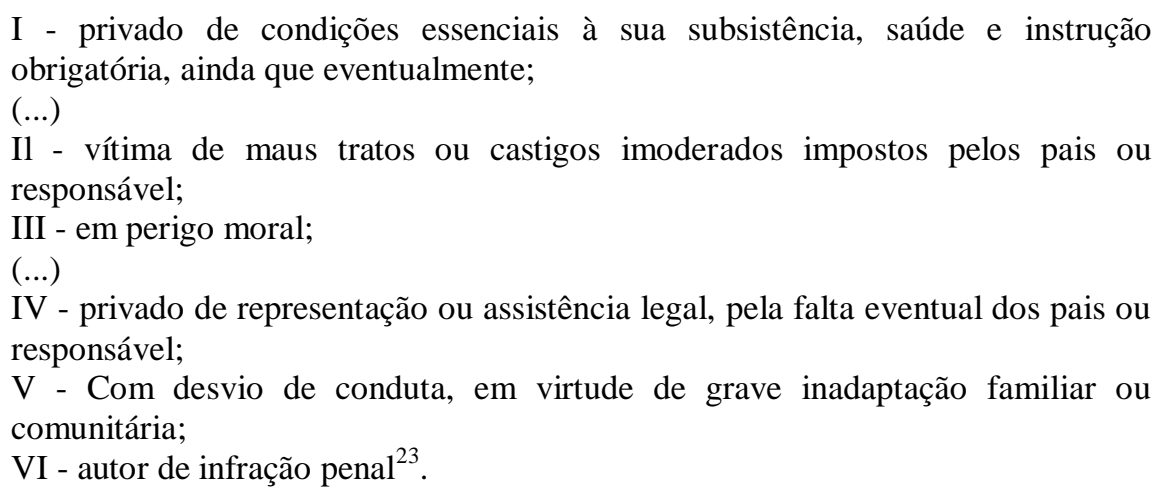

Apesar do público alvo da legislação ser bastante mais amplo que aquele da lei de 1927, o qual se resumia aos abandonados e delinquentes, o desenvolvimento dos artigos deixa transparecer seu viés punitivo, uma vez que as medidas aplicáveis ao menor parecem sugerir ações voltadas apenas aos considerados infratores ou em vias de o ser. Eram medidas aplicáveis aos menores: a) advertência; b) entrega aos pais ou responsável, ou a pessoa idônea, mediante termo de responsabilidade; c) colocação em lar substituto; d) 
imposição do regime de liberdade assistida; e) colocação em casa de semiliberdade; f) internação em estabelecimento educacional, ocupacional, psicopedagógico, hospitalar, psiquiátrico ou outro adequado ${ }^{24}$.

É no Título II, Capítulo II, Da apuração da infração penal, que se encontram as orientações sobre a aplicabilidade das medidas aos autores de infração penal. Uma vez apresentado à autoridade competente um menor de dez anos de idade, a lei parecera sugerir a não determinação de penalidade. O Art. 102 afirma que a autoridade poderia dispensá-lo de apresentação ao Juiz de Menores, enquanto o Art. 103 manifesta, apenas, o desejo de que o dano seja reparado, sempre que possível ${ }^{25}$.

Para os maiores de 10 e menores de quatorze anos, a orientação era a apresentação à autoridade competente e a apreensão do menor, no caso de caracterizar-se um flagrante delito, ou até que se apurassem as circunstâncias do sinistro. Quer dizer, flagrante ou não, a lei permitira, a partir dos 14 anos, a reclusão de menores para averiguação bem como a internação provisória - à espera de sentença - fosse em estabelecimento apropriado ou em seção distinta daquela destinada ao público adulto, em departamentos de polícia. As medidas previstas aos maiores de 14 e menores de dezoito anos eram as mesmas. A decisão sobre manter ou não os menores internados ou reclusos até que se averiguassem detalhes da infração ou como medida de segurança cabia exclusivamente ao Juiz de Menores, autoridade máxima na execução da lei em questão.

Com relação à internação, a lei a definia como medida de caráter excepcional, a ser determinada se fosse inviável ou malograsse todas as outras medidas previstas. Uma vez aplicada a medida da internação, o prazo máximo para revisão da mesma era de dois anos. Frente a uma cultura institucional que utilizava recorrentemente o abrigamento como solução para o abandono, o historiador Humberto Miranda lembra que, no ideário da FUNABEM, o atendimento ao menor seria realizado preferencialmente através da política de manutenção no $\operatorname{lar}^{26}$. Através dela, a instituição propalava seu desejo em distanciar-se de propostas consideradas paliativas - ou, dos males o menor - a ser utilizada apenas para os casos graves, como o dos infratores.

Em nenhuma das situações apresentadas pelo Código de Menores de 1979 estava especificado em lei o caráter da instituição de abrigamento/internação. Considerando as normativas da FUNABEM com relação à instauração de Fundações Estaduais do Bem Estar do Menor, que servissem como centro de recepção, triagem e abrigamento, acreditase que a lei permitisse que, na prática, autores de atos infracionais mais ou menos graves, 
bem como menores em outras situações irregulares ficassem alojados em uma mesma instituição. Pode-se considerar ainda que a falta desse detalhamento, em lei, objetivasse deixar ao Juiz de Menores a decisão pelo lugar para o qual o menor seria encaminhado, de acordo com as instituições existentes em cada localidade.

Diferentemente da normativa de 1927, a legislação de 1979 já sinalizava, ao menos em tese, o desejo de que o menor em conflito com a lei apenas em última instância fosse retirado da família e da comunidade de origem. A lei, pensada de forma sucinta e pragmática, traz pouco material para análise acerca do encaminhamento e da operacionalidade das medidas previstas. Vem das normativas da FUNABEM, utilizadas de maneira complementar ao Código de Menores, as contribuições mais significativas.

Segundo análise de Arno $\operatorname{Vogel}^{27}$, enquanto a noção de prevenção, tão presente no ideário da PNBEM, destinava-se ao menor carenciado, a de tratamento referia-se ao menor de conduta antissocial ou em conflito com a lei. Nenhum destes conceitos, a nosso entender, é basilar para a legislação que ora analisamos. No entanto, o assim chamado paradoxo da FUNABEM promovera a incorporação de ambas as situações - carenciados e em conflito com a lei - e de ambas as noções - tratamento e prevenção - ao ideário do internamento. De um lado, parece ter pesado certamente o acervo do SAM, enquanto estrutura e arranjo espacial voltado para a internação dos considerados infratores. De outro, “a FUNABEM parece ter subestimado uma autêntica tecnologia do internamento, dominada por certos grupos familiares, que manejavam os procedimentos necessários à internação e/ou dispunham de relações pessoais capazes de obtê-la" ${ }^{\natural 2}$. O resultado parece ter sido uma política de internação em massa, somente erradicada frente a duras críticas da sociedade civil e dos organismos internacionais, em fins da década de 1980.

\section{Internação e conflito com a lei no Estatuto da Criança e do Adolescente}

Diante de uma realidade social que apontava, de acordo com o Censo demográfico de 1980, a necessidade de extensão da rede de assistência a 20 milhões de pessoas entre 0 e 18 anos, sendo que outras 600 mil já estavam nela inseridas ${ }^{29}$, uma mudança epistemológica no âmbito das práticas sociais vigentes parecera inevitável. O ideário da democracia, da cidadania e dos direitos civis, políticos e sociais entraram com força na agenda do meado dessa década em diante, advindo em parte dos representantes de organizações internacionais tais como a Organização Internacional do Trabalho (OIT), a Anistia Internacional (AI) e o Fundo das Nações Unidas para a Infância (UNICEF). O 
contexto político vivido no Brasil encontrava-se propício, também, a tais incursões. O país saía de mais de vinte anos de governos militares e o processo de redemocratização possibilitara a emergência de tensões e debates, inclusos aqueles que se referiam ao tratamento da questão da infância e da adolescência.

De acordo com a historiadora Silvia Arend $^{30}$, a participação da sociedade civil e a atuação dos movimentos sociais fora de suma importância para a agenda dos direitos e a consequente inserção, a nível constitucional, dos preceitos da Declaração dos Direitos da Criança, sancionada pela Assembleia da ONU em 1959. A perspectiva histórica parece ter fornecido aportes fundamentais às lutas em torno da Constituinte e do ECA ao trazer para o debate as experiências bem sucedidas em termos de políticas sociais. Contudo, a partir da história recente do país fora possível também sistematizar críticas, violências e violações de direitos cometidas pelos agentes do Estado no que se referia, sobretudo, aos infantojuvenis assistidos em instituições de abrigamento ou àqueles que vivenciavam a marginalização mais de perto, como os considerados meninos e meninas de rua.

A conclusão de Irene Rizzini e Francisco Pilotti, na já clássica obra $A$ arte de Governar Crianças, demonstra o tom das lições do passado para as reflexões acerca do tempo presente, que originara o que designaram uma das leis mais avançadas do mundo, o Estatuto da Criança e do Adolescente,

fruto de participação popular sem precedentes na história da assistência à infância. A nova lei pretendeu garantir os direitos básicos de crianças e adolescentes de qualquer origem social, com absoluta prioridade. Desse modo, intentou-se romper com a ótica e prática estigmatizantes e excludentes que incidiam, em ampla escala, sobre a infância pobre, objeto precípuo das políticas de controle social, exercitadas com o auxílio de asilos, preventórios, internatos, patronatos e presídios, como registra, fartamente, a historiografia sobre o tema ${ }^{31}$.

A questão do internamento aparece historicamente, conforme demonstrado, como basilar das políticas sociais voltadas à infância e à adolescência, elemento que se procurou romper na construção do ECA. Com relação ao que nos interessa nesse estudo, a partir da concepção da criança e do adolescente como sujeitos em condição peculiar de desenvolvimento, o Estatuto instaura um novo paradigma: a partir dele não nos referimos ao autor de ato infracional como delinquente, pervertido ou criminoso, termos presentes nas legislações anteriores. Considera-se para fins jurídicos e sociais a criança e o adolescente autor de ato infracional como em situação de conflito com a lei. Importante mudança também no que diz respeito ao amálgama com o público adulto: não sendo considerado criminoso, é expressamente vetada a permanência de crianças e adolescentes em 
instituições penitenciárias ou policiais voltadas à população adulta. Passa-se da internação ao abrigamento ${ }^{32}$.

Uma vez verificada a prática de ato infracional, as medidas cabíveis são advertência, obrigação de reparar o dano, prestação de serviços à comunidade, liberdade assistida, inserção em regime de semiliberdade e internação em estabelecimento educacional. Além destas, a serem aplicadas em ordem crescente de gravidade da infração e da capacidade do adolescente em cumprir a proferida medida socioeducativa, pode-se ainda aplicar as seguintes medidas protetivas, de maneira prévia, complementar ou substitutiva às anteriores:

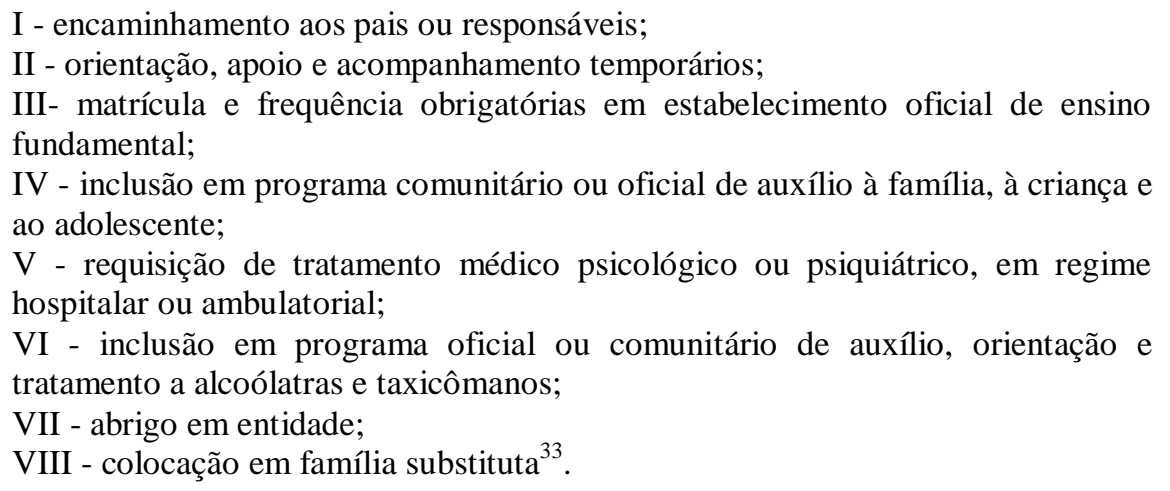

Em termos comparativos, o leque de opções previstas em lei para o atendimento e responsabilização do infantojuvenil autor de ato infracional é bastante mais amplo do que as propostas evidenciadas nas legislações anteriores.

Segundo o Art. 106, nenhum adolescente autor de ato infracional será privado de sua liberdade senão em flagrante delito ou por ordem escrita e fundamentada da autoridade jurídica competente. Já de acordo com o Art. 110, fica impossibilitada a apreensão de adolescente senão mediante o devido processo legal. A internação, antes da sentença, só poderá ser determinada pelo prazo máximo de quarenta e cinco dias e uma vez "demonstrada a necessidade imperiosa da medida" 34 .

O abrigamento em regime fechado - a dita internação - parece ser a pedra de toque das medidas socioeducativas previstas pelo ECA. Talvez devido à experiência histórica recente de internação em massa de crianças e adolescentes nas FEBEMS, aqueles que pensaram a aplicabilidade desta lei trataram de desenvolver a questão do abrigamento de maneira mais detalhada do que as demais medidas socieducativas. Como já sugerido pelo Código de 1979, no Estatuto a internação está prevista como medida excepcional, destinada aos autores de ato infracional cometido mediante grave violência à pessoa, ou para os casos 
reincidentes de outras infrações graves. Sob nenhuma hipótese a medida socioeducativa da internação aplicar-se-á quando houver outra medida adequada sem privação de liberdade, de acordo ao Art. 122, inciso II.

Com relação à aplicabilidade do regime fechado de abrigamento, esta se sujeita aos princípios da brevidade, não devendo ultrapassar três anos. Sua manutenção deve ser reavaliada, no máximo, a cada seis meses. Tendo permanecido abrigado o adolescente pelo período de três anos, outra medida deverá substituir a da internação, seja a liberdade assistida ou o regime de semiliberdade. A libertação será compulsória se o abrigado atingir a idade limite de $21 \operatorname{anos}^{35}$.

Já no que se refere aos direitos do adolescente privado de liberdade, este poderá: avistar-se reservadamente com seu defensor; peticionar diretamente a qualquer autoridade; receber visitas ao menos semanalmente; ter acesso a material de higiene e asseio pessoal; além de ser alojado em condições adequadas de higiene e salubridade; dentre outras. A condição de pessoa humana garante que tenha direito de ser tratado com dignidade e respeito, enquanto sua condição peculiar torna obrigatória a escolarização e profissionalização durante o período de abrigamento e além dele. Em nenhum caso é permitida a incomunicabilidade da criança ou do adolescente.

Não cabem dúvidas de que, em termos de promoção de direitos previstos em lei, o Estatuto está muito à frente das legislações que o precederam. Ele atualiza os termos do debate, inserindo-os na linguagem dos direitos humanos, mas também parece tentar precaver-se de arbitrariedades através da descrição largamente detalhada das medidas cabíveis a cada situação. Todavia, apesar dos avanços inegáveis, após 25 anos de sua promulgação o ECA vem sendo alvo de críticas contundentes advindas inclusive do campo do Direito; críticas que dizem respeito às dificuldades de se romper com a cultura de internação no Brasil. Aborda-se também em tom de crítica a complexidade da demanda dos direitos previstos em lei, que não acompanha a realidade evidenciada nas instituições de abrigamento com privação de liberdade, voltadas aos infantojuvenis em situação de conflito com a lei.

Segundo Paulo Roberto Sandrini ${ }^{36}$, as concepções de proteção e punição fundamentam as justificativas e as ações de controle social da adolescência brasileira historicamente, o que pode ser corroborado com a análise da legislação voltada aos infantojuvenis ao longo do século XX. No entanto, para além do que apregoa o discurso hegemônico, que considera o Estatuto um grande avanço jurídico e social na proteção da 
infância e da adolescência brasileira, este autor reflete sobre as mudanças operacionais práticas implementadas com relação aos sujeitos em conflito com a lei. Em seu entender, para além do vocabulário datado pouco fora alterado com relação às medidas imputadas a essa parcela da população infantojuvenil, desde o primeiro Código de Menores até o Estatuto da Criança e do Adolescente.

Em consonância com Osvaldo Agustín Marcón ${ }^{37}$, entendemos que os parcos avanços no sistema de responsabilização infantojuvenil no Brasil e em grande parte dos países latinoamericanos liga-se à incapacidade de entender a prática do ato infracional como fenômeno social relacional, estrutural e coletivo. Quer dizer, apesar de ser responsabilidade do Estado, da sociedade e da família zelar pelo desenvolvimento da criança e do adolescente - preceito basilar da Justiça Integradora - no caso de envolvimento em crime ou contravenção é o infantojuvenil, individualmente, quem deve arcar com a responsabilização pelo delito. As dificuldades em operar a lógica da Doutrina de Proteção Integral advêm da tensão entre pensar políticas pautadas na noção de sujeitos de direito prioritários, mas, concomitantemente, seguir aplicando medidas de responsabilização ao gosto do sistema penal-carcerário tradicional.

A Doutrina de Proteção Integral não logra consolidar uma Justiça Integradora, quiçá, haja vista que sua operacionalização significaria responsabilizar o corpo social como um todo pelo descaminho do infrator, bem como imputar à coletividade a restauração do dano causado e a erradicação das condições de sua existência. Devido a complexidade da aplicabilidade dessa concepção de Justiça, tem-se, como no ECA, uma Doutrina de Proteção Integral pautada, em parte, em uma Justiça Penal, ainda que infantojuvenil, o que torna essa legislação, no mínimo, ambígua.

\section{Considerações finais}

Para os domínimos da História, a relevância de traçar os caminhos da penalização infantojuvenil até o tempo presente gira em torno dos avanços em passos lentos com relação à temática, bem como da ameaça constante de retrocessos. Desde o ano 1990, quando o Estatuto foi promulgado e os menores de 18 anos foram definitivamente considerados inimputáveis - ainda que se leve em consideração as críticas aqui apontadas muitas propostas que visam à alteração seja da idade de responsabilidade penal ou das medidas socioeducativas voltadas aos infratores foram enviadas à Câmada dos Deputados, no Brasil. Atualmente tem-se a Proposta de Emenda Constitucional n. 171, de $1993^{38}$, 
aprovada em primeira e segunda instância por essa Câmara, aguardando ser encaminhada para os demais foros. Se aprovada, a lei permitirá que adolescentes entre 16 e 18 anos sejam sentenciados ao modelo do público adulto em caso de crime/ contravenção grave, embora em instituições específicas. O que está em jogo nesse debate, que vem à tona tão frequentemente no Brasil? Por que a insistência na alteração da legislação que diz respeito aos atos infracionais cometidos por infantojuvenis se o Estatuto já prevê a medida da internação em regime fechado pelo período de até três anos em casos de ato infracional grave contra a pessoa humana?

Para iluminar perspectivas que contribuam na resolução do questionamento acima sugerido, aproximamo-nos do parecer da antropóloga Patrice Schuch, que assinala a universalização da noção de infância e juventude enquanto sujeitos de direitos como processo que envolve mais do que transformar leis: trata-se de modificar práticas sociais de geração de desigualdades ${ }^{39}$. Trata-se, ainda, de dar atenção para a complexidade das situações que configuram estas desigualdades, buscando expandir as alternativas para sua transformação em termos de justiça social.

Ainda que não tenhamos adentrado no âmbito da operacionalização das leis aqui analisadas, é latente no tempo presente a tentativa de romper com o ideário da internação/abrigamento voltado aos infantojuvenis em situação de conflito com a lei, marca indelével do sistema penal/punitivo que tem por objetivo a diminuição dos riscos sociais através do isolamento, e não a efetiva ressocialização dos indivíduos. Basta um olhar nas informações disponíveis sobre rebeliões nos centros de internação para perceber que muito pouco parece se ter avançado nesse sentido: as instituições apresentam-se insalubres, superlotadas e a violação dos direitos fundamentais à pessoa em condição peculiar de desenvolvimento é denúncia constante.

O estudo da legislação infantojuvenil e especificamente, daquelas normativas que pautaram as ações voltadas aos inimputáveis em conflito com a lei, no século XX, deixanos um parecer saliente. Consideramos importante avaliar quais são as contradições sociais evidenciadas na sociedade brasileira que dificultam a consolidação do ideário dos direitos e da condição peculiar do desenvolvimento quando se trata dos adolescentes autores de atos infracionais. Como historiadores e historiadoras, nos intrigam as modificações operadas no campo do discurso que, para além da criação de obstáculos, inviabilizam a aplicação do Estatuto da Criança e do Adolescente, principalmente em relação aos considerados 
infratores, enquanto noutras temáticas evidencia-se um processo consolidado de sensibilização social ${ }^{40}$.

\section{Notas}

${ }^{1}$ O termo menor é oriundo das fontes documentais deste estudo, não fazendo referência à nossa compreensão
acerca da população infantojuvenil. Optamos por trabalhar com essa categoria de maneira destacada do resto
do texto, em itálico, buscando evitar certa confusão entre as citações da fonte e nossa análise. Em
concordância com a historiadora Eleonora Brito, entendemos que a experiência da FUNABEM inventa o
menor, "consolidação não só de um vocábulo numa determinada ascepção - crianças e jovens perigosos ou
postos em perigo" - mas também de um sujeito que será alvo de práticas de intervenção social e judiciárias.
BRITO, Eleonora Zicari Costa de. Justiça e Gênero: uma história da Justiça de Menores em Brasília (19601990). Brasília: Editora da Universidade de Brasília, 2007. p. 115.

${ }^{2}$ VOGEL, Arno. Do Estado ao Estatuto: propostas e vicissitudes da política de atendimento à infância e adolescência no Brasil contemporâneo. In: RIZZINI, Irene; PILOTTI, Francisco (Orgs.). A Arte de Governar Crianças: a história das políticas sociais, da legislação e da assistência à infância no Brasil. $3^{\mathrm{a}}$ ed. São Paulo: Cortez Editora, 2011. p. 301.

${ }^{3} \mathrm{O}$ debate com a legislação infantojuvenil do século XX faz parte dos estudos de doutoramento da autora, sobre a criminalização da menoridade durante a vigência da Política Nacional do Bem Estar do Menor.

${ }^{4}$ SILVA, Jeanne. Relações entre História e Direito: o Direito como campo de pesquisa histórica e a História como contribuição ao avanço do Direito. Revista Projeto História. n. 41. História, Historiadores, Historiografia. 2010. pp. 543-555.

${ }^{5}$ Ibidem, p. 553.

${ }^{6}$ BOURDIEU, Pierre. A força do Direito. Elementos para uma sociologia do campo jurídico. In: $\mathbf{O}$

Poder Simbólico. Rio de Janeiro: Bertrand, 1989. pp. 209-254.

${ }^{7}$ A opção pelo estudo da lei e não pela operacionalização da mesma se pauta em grande medida na impossibilidade de analisar a aplicação de uma doutrina jurídica em termos de nação. No caso do Brasil, cujo território tem proporções continentais, as políticas sociais ao longo do século XX se efetivaram a partir dos estados e/ou distrito, seguindo coordenadas dos contextos políticos estaduais.

${ }^{8}$ RIZZINI, Irene. Crianças e menores: do pátrio poder ao pátrio dever. In: __ ; PILOTTI, Francisco (Orgs.). A Arte de Governar Crianças: a história das políticas sociais, da legislação e da assistência à infância no Brasil. $3^{\text {a }}$ ed. São Paulo: Cortez Editora, 2011. pp. 97-149.

9 AREND, Silvia Maria Fávero. Legislação menorista para o trabalho: infância em construção. Caderno Espaço Feminino, v. 17, n. 1, jan./jul. 2007. p. 277-278.

${ }^{10}$ RIZZINI, 2011, p. 133.

${ }^{11}$ SANTOS, Marco Antônio Cabral dos. Criança e criminalidade no início do século. In: DEL PRIORE, Mary (Org.). História das Crianças no Brasil. $6^{a}$ ed. São Paulo: Contexto, 2009. p. 214.

12 BRASIL. Código Penal dos Estados Unidos do Brazil. Decreto n. 847, de 11 de outubro de 1890. Disponível em: http://legis.senado.gov.br/legislacao/ListaPublicacoes.action?id=66049.

${ }^{13}$ Ambas as instituições foram criadas na cidade de São Paulo, segundo Santos, durante a década de 1900. SANTOS, 2009, p. 224.

${ }^{14}$ Ibidem, p. 214.

${ }^{15}$ BRASIL. Código de Menores de 1927. Decreto-Lei n. 17.493-A, de 12 de outubro de 1927. Cap. VII, Art. 68. Disponível em: http://www.planalto.gov.br/ccivil_03/decreto/1910-1929/D17943Aimpressao.htm.

${ }^{16}$ Ibidem, Arts. 86 e 87.

${ }^{17}$ SEGUNDO, Rinaldo. Notas sobre o direito da Criança. Revista Jus Navigandi, Teresina, ano 8, n. 61, jan. 2003. Disponível em: http://jus.com.br/artigos/3626/notas-sobre-o-direito-da-crianca. Acesso em: 13/12/2015. $\mathrm{s} / \mathrm{p}$.

${ }^{18}$ DAMINELLI, Camila Serafim. Governar, assistir, tolerar: uma história sobre infância e juventude em Florianópolis através das páginas de $O$ Estado (1979-1990). Dissertação. Mestrado em História. Universidade Federal de Santa Catarina, 2013. Disponível em: https://repositorio.ufsc.br/bitstream/handle/123456789/107139/317827.pdf.

${ }^{19}$ RIZZINI, Irma. Meninos desvalidos e menores transviados: a trajetória da assistência pública até a Era Vargas. In: RIZZINI, Irene; PILOTTI, Francisco (Orgs.). A Arte de Governar Crianças: a história das 
políticas sociais, da legislação e da assistência à infância no Brasil. $3^{\mathrm{a}}$ ed. São Paulo: Cortez Editora, 2011. pp. $225-286$.

${ }^{20}$ VOGEL, 2009, p. $287-288$.

${ }^{21}$ Ibidem, idem.

22 Ibidem, idem.

23 BRASIL. Novo Código de Menores. Lei n. 6.697, de 10 de outubro de 1979. Disponível em: http://www.planalto.gov.br/ccivil_03/leis/1970-1979/L6697impressao.htm.

${ }^{24}$ Ibidem, Cap. I, Art. 14.

${ }^{25}$ Ibidem, Cap. II.

${ }^{26}$ MIRANDA, Humberto da Silva. A cor do abandono: as crianças em situação de rua no Recife na ditadura civil-militar (1964-1985). Revista Tempo e Argumento, Florianópolis, v.7, n. 14. jan./abr. 2015. p. 165.

${ }^{27}$ VOGEL, 2009, p. 295.

${ }^{28}$ Ibidem, p. 299.

29 AREND, Silvia Maria Fávero. "Sopram novos ventos...”: Legislação e noção de família no período de democratização (Brasil, 1980-1990). Anais do XIV Encontro Estadual de História -“Tempo, memórias e expectativas", 19 a 22 de agosto de 2012, Universidade do Estado de Santa Catarina - UDESC, Florianópolis, SC. p. 05. Disponível em: http://www.anpuhsc.org.br/encontro2012/uploads/simposio-06-trabalho-18.pdf.

${ }^{30}$ Ibidem, p. 06.

${ }^{31}$ RIZZINI, Irene; PILOTTI, Francisco (Orgs.). Conclusão: A arte de governar crianças: lições do passado reflexões para o presente. In: A Arte de Governar Crianças: a história das políticas sociais, da legislação e da assistência à infância no Brasil. $3^{\mathrm{a}}$ ed. São Paulo: Cortez Editora, 2011. p. 323.

${ }^{32}$ Essas tranformações conceituais, somadas a termos-chave como direitos, absoluta prioridade, condição peculiar de desenvolvimento, dentre outros, definiram como veio a ser chamado o Estatuto: uma Doutrina de Proteção Integral. Essa doutrina vem sendo elaborada pelas organizações internacionais através, por exemplo, da Declaração dos Direitos da Criança (1959), das Regras Mínimas de Beijing (1985) e da Convenção dos Direitos da Criança (1989).

${ }^{33}$ BRASIL. Estatuto da Criança e do Adolescente. Lei n. 8069, de 12 e outubro de 1990. Cap. II, Art. 101. Disponível em: http://www.planalto.gov.br/ccivil_03/LEIS/L8069.htm.

${ }^{34}$ Ibidem, Art. 108.

${ }^{35}$ Ibidem, Art. 121, inciso $5^{\circ}$.

${ }^{36}$ SANDRINI, Paulo Roberto. O controle social da adolescência brasileira: gênese e sentidos do Estatuto da Criança e do Adolescente. Doutorado em Ciências Humanas. Florianópolis: Universidade Federal de Santa Catarina, 2009. p. 110-111.

${ }^{37}$ MARCÓN, Orvaldo Agustín. La responsabilidad del niño que delinque. Revista Katál, Florianópolis, v. 11, n. 2, jul./dez. 2008. Disponível em: http://www.scielo.br/scielo.php?cript=sci_arttext\&pid=S141449802008000200009. p. 242-243.

${ }^{38}$ Estão apenadas à PEC 171/1993 dezenas de outras semelhantes, agrupadas por afinidade, além de duas cuja votação ocorrerá separadamente. São elas: a PEC n. 20/1999 e a PEC n. 90/2003, ambas oriundas do Senado Federal. A redução da idade de imputabilidade penal, parcial ou integral, é o objeto dessas três Propostas de Emenda Constitucional e das respectivas propostas apenadas.

${ }^{39}$ SCHUCH, Patrice. Os direitos da criança na encruzilhada: os princípios da igualdade versus os princípios da diferença (1990-2000). In: SCHREINER, Davi Félix; PEREIRA, Ivonete; AREND, Silvia Maria Fávero (Orgs.). Infâncias brasileiras: experiências e discursos. Cascavel: Ed. Unioeste, 2009. p. 274-275.

${ }^{40}$ AREND, 2012, p. 03-04.

\section{Referências Bibliográficas}

AREND, Silvia Maria Fávero. Legislação menorista para o trabalho: infância em construção. Caderno Espaço Feminino, v. 17, n. 1, jan./jul. 2007. pp. 269-292.

. "Sopram novos ventos...": Legislação e noção de família no período de democratização (Brasil, 1980 - 1990). Anais do XIV Encontro Estadual de História "Tempo, memórias e expectativas", 19 a 22 de agosto de 2012, Universidade do Estado de Santa Catarina - UDESC, Florianópolis, SC. 10p. Disponível em: http://www.anpuhsc.org.br/encontro2012/uploads/simposio-06-trabalho-18.pdf. 
BOURDIEU, Pierre. A força do Direito. Elementos para uma sociologia do campo jurídico. In: O Poder Simbólico. Rio de Janeiro: Bertrand, 1989. pp. 209-254.

BRITO, Eleonora Zicari Costa de. Justiça e Gênero: uma história da Justiça de Menores em Brasília (1960-1990). Brasília: Editora da Universidade de Brasília, 2007.

DAMINELLI, Camila Serafim. Governar, assistir, tolerar: uma história sobre infância e juventude em Florianópolis através das páginas de O Estado (1979-1990). Dissertação. Mestrado em História. Universidade Federal de Santa Catarina, 2013. 198p. Disponível em: https://repositorio.ufsc.br/bitstream/handle/123456789/107139/317827.pdf.

MARCÓN, Orvaldo Agustín. La responsabilidad del niño que delinque. Revista Katál, Florianópolis, v. 11, n. 2, jul./dez. 2008. pp. 237-247. Disponível em: http://www.scielo.br/scielo.php?cript=sci_arttext\&pid=S1414-49802008000200009.

MIRANDA, Humberto da Silva. A cor do abandono: as crianças em situação de rua no Recife na ditadura civil-militar (1964-1985). Revista Tempo e Argumento, Florianópolis, v.7, n. 14, jan./abr. 2015. pp. 155-179.

RIZZINI, Irene. Crianças e menores: do pátrio poder ao pátrio dever. In: ; PILOTTI, Francisco (Orgs.). A Arte de Governar Crianças: a história das políticas sociais, da legislação e da assistência à infância no Brasil. $3^{a}$ ed. São Paulo: Cortez Editora, 2011. pp. 97-149.

PILOTTI, Francisco (Orgs.). Conclusão: A arte de governar crianças: lições do passado reflexões para o presente. In: A Arte de Governar Crianças: a história das políticas sociais, da legislação e da assistência à infância no Brasil. $3^{\mathrm{a}}$ ed. São Paulo: Cortez Editora, 2011. pp. 323-329.

RIZZINI, Irma. Meninos desvalidos e menores transviados: a trajetória da assistência pública até a Era Vargas. In: RIZZINI, Irene; PILOTTI, Francisco (Orgs.). A Arte de Governar Crianças: a história das políticas sociais, da legislação e da assistência à infância no Brasil. $3^{a}$ ed. São Paulo: Cortez Editora, 2011. pp. 225-286.

SANDRINI, Paulo Roberto. O controle social da adolescência brasileira: gênese e sentidos do Estatuto da Criança e do Adolescente. Doutorado em Ciências Humanas. Florianópolis: Universidade Federal de Santa Catarina, 2009. 164p.

SANTOS, Marco Antônio Cabral dos. Criança e criminalidade no início do século. In: DEL PRIORE, Mary (Org.). História das Crianças no Brasil. 6 ${ }^{a}$ ed. São Paulo: Contexto, 2009. pp. 210-230.

SCHUCH, Patrice. Os direitos da criança na encruzilhada: os princípios da igualdade versus os princípios da diferença $(1990$ - 2000). In: SCHREINER, Davi Félix; PEREIRA, Ivonete; AREND, Silvia Maria Fávero (Orgs.). Infâncias brasileiras: experiências e discursos. Cascavel: Ed. Unioeste, 2009. pp. 257-275.

SEGUNDO, Rinaldo. Notas sobre o direito da Criança. Revista Jus Navigandi, Teresina, ano 8, n. 61, jan. 2003. Disponível em: http://jus.com.br/artigos/3626/notas-sobre-odireito-da-crianca. Acesso em: 13/12/2015. s/p.

SILVA, Jeanne. Relações entre História e Direito: o Direito como campo de pesquisa histórica e a História como contribuição ao avanço do Direito. Revista Projeto História. n. 41. História, Historiadores, Historiografia. 2010. pp. 543-555.

VOGEL, Arno. Do Estado ao Estatuto: propostas e vicissitudes da política de atendimento à infância e adolescência no Brasil contemporâneo. In: RIZZINI, Irene; PILOTTI, Francisco (Orgs.). A Arte de Governar Crianças: a história das políticas sociais, da legislação e da assistência à infância no Brasil. $3^{\text {a }}$ ed. São Paulo: Cortez Editora, 2011. pp. 287-321. 


\section{Legislação}

BRASIL. Código Penal dos Estados Unidos do Brazil. Decreto n. 847, de 11 de outubro de 1890. Disponível

em: http://legis.senado.gov.br/legislacao/ListaPublicacoes.action?id=66049

BRASIL. Código de Menores de 1927. Decreto-Lei n. 17.493-A, de 12 de outubro de 1927. Disponível em: http://www.planalto.gov.br/ccivil_03/decreto/19101929/D17943Aimpressao.htm.

BRASIL. Novo Código de Menores. Lei n. 6.697, de 10 de outubro de 1979. Disponível em: http://www.planalto.gov.br/ccivil_03/leis/1970-1979/L6697impressao.htm.

BRASIL. Estatuto da Criança e do Adolescente. Lei n. 8069, de 12 e outubro de 1990. Disponível em: http://www.planalto.gov.br/ccivil_03/LEIS/L8069.htm. 